\title{
Limitations of caspofungin in the treatment of obstructive pyonephrosis due to Candida glabrata infection Silke Schelenz ${ }^{* 1}$ and Calum N Ross ${ }^{2}$
}

Address: ${ }^{1}$ Microbiology Department, Norfolk and Norwich University Hospital, UK and ${ }^{2}$ Department of Renal Medicine, Norfolk and Norwich University Hospital, UK

Email: Silke Schelenz* - sschelenz@doctors.org.uk; Calum N Ross - calum.ross@nnuh.nhs.uk

* Corresponding author

Published: 08 August 2006

BMC Infectious Diseases 2006, 6:126 doi:10.1/86/147/-2334-6-126
Received: 27 April 2006

Accepted: 08 August 2006

This article is available from: http://www.biomedcentral.com/I47I-2334/6/I26

(c) 2006 Schelenz and Ross; licensee BioMed Central Ltd.

This is an Open Access article distributed under the terms of the Creative Commons Attribution License (http://creativecommons.org/licenses/by/2.0), which permits unrestricted use, distribution, and reproduction in any medium, provided the original work is properly cited.

\begin{abstract}
Background: Caspofungin is a new antifungal agent with high-level activity against a number of Candida species including those that are resistant to azoles. Its good safety profile and low nephrotoxicity makes it an attractive drug to treat fungal infections in patients with compromised renal function. However, little is known about the clinical efficacy in the treatment of complicated urinary tract infections due to Candida species such as pyonephrosis.

Case presentation: We report a case of obstructive pyonephrosis due to an azole (fluconazole and itraconazole) resistant Candida glabrata strain that failed to respond to intravenous treatment with caspofungin. A sustained clinical and microbiological response was only achieved after percutaneous drainage and instillation of amphotericin B deoxycholate into the renal pelvis in combination with intravenous liposomal amphotericin B.

Conclusion: This case demonstrates the limitation of intravenous antifungal agents such as caspofungin as the sole treatment of an obstructive upper urinary tract infection due to Candida species. In order to achieve long term sustained cure from an obstructive pyonephrosis, pus and fungal balls should be drained and an anti-fungal agent such as amphotericin $B$ deoxycholate instilled locally. The pharmacokinetics and role of caspofungin in the treatment of complicated Candida urinary tract infection is reviewed.
\end{abstract}

\section{Background}

Pyonephrosis refers to infected purulent urine in an obstructed urinary collecting system such as the renal pelvices. Although bacteria cause the majority of these infections, Candida species such as C. glabrata have been reported to be involved in $5 \%$ of cases [1].

We describe a case of pyonephrosis complicated by candidaemia due to an azole (fluconazole and itraconazole) resistant C. glabrata that had not resolved after treatment with intravenous (iv) caspofungin. Caspofungin is a novel antifungal agent belonging to the class of echinocandins with good antifungal activity against Candida species including azole resistant strains [2]. It is recommended for the treatment of candidaemia and other serious invasive Candida infections [3]. The role of antifungal agents and the importance of percutaneous nephrostomy drainage in the conservative management of Candida pyonephrosis is discussed. 


\section{Case presentation}

A 71-year-old lady with type II diabetes mellitus, treated with insulin, presented in February 2004 with acute renal failure due to bilateral ureteric obstruction and hydronephrosis. Six months prior to this acute admission, the patient was treated empirically with fluconazole for a histologically proven necrotising Candida infection of the bladder. Her acute obstruction was managed by the insertion of bilateral nephrostomy catheters. On the day of the procedure she developed rigors, vomiting and right loin pain despite antibiotic cover with amoxicillin (500 mg tds). She was pyrexial $\left(38.9^{\circ} \mathrm{C}\right)$, her inflammatory markers were increased (WBC $23.2 \times 10^{9} / 1$, neutrophils $21.8 \times$ 10\%/l, CRP $300 \mathrm{mg} / \mathrm{l}$ ) and her renal function compromised (creatinine $333 \mu \mathrm{mol} / \mathrm{l}$ ). The blood and nephrostomy urine cultures grew a non- albicans Candida species. The pre-morbid history suggested that the current nonalbicans Candida isolate might be an azole-resistant strain and on the basis of her acute renal failure, the patient was commenced on empirical intravenous liposomal amphotericin B (AmBisome $1 \mathrm{mg} / \mathrm{kg} / \mathrm{od}$ ). The organism was subsequently identified as C.glabrata with reduced susceptibility to fluconazole and itraconazole MIC fluconazole $16.0 \mathrm{mg} / \mathrm{l}$, itraconazole $1.0 \mathrm{mg} / \mathrm{l}$ ) but susceptible to amphotericin B (MIC $1.0 \mathrm{mg} / \mathrm{l}$ ), caspofungin (MIC 0.5 $\mathrm{mg} / \mathrm{l})$, voriconazole $(\mathrm{MIC}<0.03 \mathrm{mg} / \mathrm{l})$.

The patient was treated for four weeks with iv liposomal amphotericin B during which time her left nephrostomy tube was replaced by a ureteric stent. Four months later she was readmitted to the hospital for an elective right ureteric stent insertion but she developed a severe urosepsis (temperature $39.4^{\circ} \mathrm{C}, \mathrm{WBC} 45.5 \times 10^{9} / \mathrm{l}, \mathrm{CRP}>300$ $\mathrm{mg} / \mathrm{l}$, creatinine $407 \mu \mathrm{mol} / \mathrm{l})$ during the procedure which was abandoned. AmBisome (1 $\mathrm{mg} / \mathrm{kg} / \mathrm{od})$ was given shortly after the procedure but did not prevent the need for intensive care support. Blood cultures and urostomy urine again grew the azole resistant C.glabrata. Due to the recurrence of Candida sepsis despite previous treatment with amphotericin $\mathrm{B}$ and because of her acute renal failure it was felt that a different class of anti-fungal agent with good activity against C.glabrata and minimal nephrotoxicity should be used. Amphotericin B was therefore stopped after three days and replaced by iv caspofungin $(70 \mathrm{mg}$ loading dose, $50 \mathrm{mg}$ od). Caspofungin was continued for 12 days during which time her blood and catheter urine became sterile and her inflammatory markers and temperature normalised.

However, as the stenting of her right kidney was unsuccessful, attributed to multiple intra-renal strictures and irregularity of the urothelial outline, a percutaneous nephrostomy tube was inserted to allow long-term drainage. This time AmBisome was given one day prior to the procedure and continued for a total of 11 days during which time no sepsis occurred. Nevertheless, nephrostomy fluid analysis revealed large numbers of pus and yeast cells and again grew the azole resistant C.glabrata. Because of the persistent $C$. glabrata infection of the renal pelvices, despite treatment with iv liposomal amphotericin B followed by a course of caspofungin, it was felt that active local irrigation with amphotericin B was necessary to reduce the fungal load and to ensure that the antifungal agent achieved the site of infection. Five $\mathrm{ml}$ of conventional amphotericin B (Fungizone, $200 \mu \mathrm{g} / \mathrm{ml}$ ) was instilled into the nephrostomy tube which was then clamped for 30-60 minutes at a time. This procedure was repeated four times daily for four days. A urostomy sample of urine taken 48 hours later continued to grow C. glabrata and treatment was therefore repeated for a further five days in combination with iv liposomal amphotericin B. Subsequently the urine sterilised and routine monthly urine cultures remained negative. The patient has had no further recurrence of the Candida infection during a 16 month follow up.

\section{Discussion}

C. glabrata is an emerging pathogen and it is now the most common non-albicans species causing candidaemia [4]. This organism is increasingly resistant to the first line antifungal agent fluconazole which poses a challenge in the treatment of serious Candida infections [3,4]. The conventional treatment of azole resistant Candida strains often requires traditional agents such as amphotericin $B$, which can cause nephrotoxicity. Caspofungin belongs to a new group of antifungals, the echinocandins, which is highly active against azole resistant non-albicans Candida species. It demonstrates good activity in vitro against C. glabrata with MICs ranging between of $0.19-2 \mu \mathrm{g} / \mathrm{ml}$ although the drug might not always be fungicidal against this pathogen $[2,5,6]$.

Clinical trials with caspofungin have shown good efficacy in the treatment of candidaemia, Candida oesophagitis and individual case reports have shown treatment successes with other serious Candida infections such as endocarditis [6-8]. The drug is well tolerated and, due to its principally hepatic excretion, it is safe to use in renal failure [6].

Very little is known about the clinical efficacy of caspofungin in the treatment of complicated fungal urinary tract infections such as pyonephrosis. Animal studies have shown that caspofungin can be detected in kidney tissue at concentrations three times that of plasma levels 24 hours after injection [9]. Similar pharmacokinetics were reported by Stone et al. who detected $4.2 \%$ of the original caspofungin dose in animal kidneys versus $35.2 \%$ in liver tissue after 24 hours [10]. Experiments in mice have also demonstrated that caspofungin can significantly reduce 
the C.glabrata tissue burden in kidneys at doses as low as $0.3 \mathrm{mg} / \mathrm{kg} /$ day although organ sterilization may only occur at much higher drug doses of $5 \mathrm{mg} / \mathrm{kg} /$ day or in combination with amphotericin B $[5,11]$.

Unfortunately, the drug concentration in the kidney does not reflect availability in the urine. In healthy individuals, only a small fraction (1.44\%) of the original drug can be detected after 24 hours in the urine after a single iv dose $[10,12]$. Caspofungin may therefore not be the drug of choice in the treatment of serious urinary tract infections although more clinical data is needed to fully assess the role of this drug for the treatment of such infections.

Another important issue in the management of pyonephrosis is the accumulation of pus and fungi in an obstructed space, the renal pelvices. As with other enclosed bacterial infections such as empyemas, drainage of the pus is of fundamental importance and may explain why systemic treatment with antifungals such as amphotericin $\mathrm{B}$, caspofungin or fluconazole alone have proven to be unsuccessful $[13,14]$.

In cases of pyonephrosis the insertion of a percutaneous nephrostomy tube allows urinary diversion with subsequent improvement in renal function and also enables the local administration of an anti-fungal drug directly to the site of infection [15]. Our case report supports the sparse literature suggesting that drainage via a percutaneous nephrostomy tube combined with the local instillation in combination with systemic use of an antifungal agent such as caspofungin or amphotericin B is necessary to successfully manage such an infection $[13,14]$. Other antifungal drugs such as flucytosine or voriconazole may also need to be considered.

\section{Conclusion}

The intravenous anti-fungal drugs such as caspofungin or amphotericin B are useful in treating or preventing candidaemia during instrumentation such as insertion of nephrostomy tubes in cases of Candida pyonephrosis. However, they are unlikely to lead to a cure of this infection if used as the sole treatment. Conservative management should also include local drainage of pus and fungi as well as instillation of an effective antifungal agent into the pelvices.

\section{Abbreviations}

MIC: minimal inhibitory concentration

\section{Competing interests}

The author(s) declare that they have no competing interests.

\section{Authors' contributions}

SS wrote the manuscript and was involved with the patients management. CNR cared for the patient and contributed to the writing of the manuscript. All authors read and approved the final manuscript.

\section{Acknowledgements}

Written consent was obtained from the patient for publication of the study.

\section{References}

I. Ng CK, Yip SK, Sim LS, Tan BH, Wong MY, Tan BS, Htoo A: Outcome of percutaneous nephrostomy for the management of pyonephrosis. Asian J Surg 2002, 25:215-9.

2. Barchiesi F, Schimizzi AM, Fothergill AW, Scalise G, Rinaldi MG: In vitro activity of new echinocandin antifungal, MK-099 I against common and uncommon clinical isolates of Candida species. Eur J Clin Microbiol Infect Dis 1999, I 8:302-304.

3. Pappas PG, Rex JH, Sobel JD, et al.: Guidelines for treatment of candidiasis. Clin Infect Dis 2004, 38:16I-I89.

4. Schelenz S, Gransden WR: Candidaemia in a London teaching hospital: analysis of 128 cases over a 7-year period. Mycoses 2003, 46:390-6.

5. Barchiesi F, Spreghini E, Tomassetti S, Arzeni D, Giannini D, Scalise G: Comparison of the fungicidal activities of caspofungin and amphotericin B against Candida glabrata. Antimicrob Agents Chemother 2005, 49:4989-92.

6. Mora-Duarte J, Betts R, Rotstein C, Colombo AL, Thompson-Moya L, Smietana J, Lupinacci R, Sable C, Kartsonis N, Perfect J: Caspofungin Invasive Candidiasis Study Group. Comparison of caspofungin and amphotericin B for invasive candidiasis. $N$ Engl J Med 2002, 347:2020-2029.

7. Villanueva A, Gotuzzo E, Arathoon EG, Noriega LM, Kartsonis NA, Lupinacci RJ, Smietana JM, DiNubile MJ, Sable CA: A randomized double-blind study of caspofungin versus fluconazole for the treatment of esophageal candidiasis. Am J Med 2002, I I 3:294-299.

8. Lye DC, Hughes A, O'Brien D, Athan E: Candida glabrata prosthetic valve endocarditis treated successfully with fluconazole plus caspofungin without surgery: a case report and literature review. Eur J Clin Microbiol Infect Dis 2005, 24:753-755.

9. Hajdu R, Thompson R, Sundelof JG, Pelak BA, Bouffard FA, Dropinski JF, Kropp H: Preliminary animal pharmacokinetics of the parenteral antifungal agent MK-099 I (L-743,872). Antimicrob Agents Chemother 1997, 41:2339-2344.

10. Stone JA, Xu X, Winchell GA, Deutsch PJ, Pearson PG, Migoya EM, Mistry GC, Xi L, Miller A, Sandhu P, Singh R, deLuna F, Dilzer SC, Lasseter KC: Disposition of caspofungin: role of distribution in determining pharmacokinetics in plasma. Antimicrob Agents Chemother 2004, 48:815-23.

II. Barchiesi F, Spreghini E, Fothergill AW, Arzeni D, Greganti G, Giannini D, Rinaldi MG, Scalise G: Caspofungin in combination with amphotericin B against Candida glabrata. Antimicrob Agents Chemother 2005, 49:2546-9.

12. Balani SK, Xu X, Arison BH, Silva MV, Gries A, DeLuna FA, Cui D, Kari PH, Ly T, Hop CE, Singh R, Wallace MA, Dean DC, Lin JH, Pearson PG, Baillie TA: Metabolites of caspofungin acetate, a potent antifungal agent, in human plasma and urine. Drug Metab Dispos 2000, 28: I 274-I 278.

13. Arend SM, Kuijper EJ, de Vaal BJ, de Fijter JW, Van't Wout JW: Successful treatment of fungus balls due to fluconazole-resistant Candida sake obstructing ureter stents in a renal transplant patient. Eur J Clin Microbiol Infect Dis 2005, 20: 1-3.

14. Clark MA, Gaunt T, Czachor JS: The use of fluconazole as a local irrigant for nephrostomy tubes. Mil Med 1999, I64:239-24I.

15. Bell DA, Rose SC, Starr NK, Jaffe RB, Miller FJ Jr: Percutaneous nephrostomy for nonoperative management of fungal urinary tract infections. J Vasc Interv Radiol 1993, 4:3 I I-5.

\section{Pre-publication history}

The pre-publication history for this paper can be accessed here: 
http://www.biomedcentral.com/1471-2334/6/126/pre

pub

Publish with Biomed Central and every scientist can read your work free of charge

"BioMed Central will be the most significant development for disseminating the results of biomedical research in our lifetime. " Sir Paul Nurse, Cancer Research UK

Your research papers will be:

- available free of charge to the entire biomedical community

- peer reviewed and published immediately upon acceptance

- cited in PubMed and archived on PubMed Central

- yours - you keep the copyright 